\title{
O OLHAR DO OUTRO: A GESTÃO DE MUSEUS E A SUSTENTABILIDADE NA MUSEOLOGIA
}

\author{
Júlio César Bittencourt Francisco' \\ Universidade Federal do Rio Grande do Sul \\ Valdir José Morigi ${ }^{2}$ \\ Universidade Federal do Rio Grande do Sul
}

\section{RESUMO:}

Reflete sobre a prática museológica e o papel da Gestão de Museus no século XXI.Os Museus através de seus acervos, espécimes e equipamentos têm a missão de divulgar a cultura, comunicar os bens da memória social, além de educar e entreter os cidadãos. Entretanto, essas atividades essenciais precisam ser repensadas, pois já não satisfazem as necessidades dos novos tempos. $O$ estudo propõe a construção do Plano Museológico como prática de Gestão de Museus a partir da Política Nacional de Museus e da análise de dois manuais de gestão museal e de programas socioambientais em Museus brasileiros. Conclui-se que a prática museológica também deve fomentar a participação ativa da comunidade em questões socioambientais e do exercício pleno da cidadania, colocando-se como instituição que possibilita a reflexividade dos sujeitos diante da realidade.

PALAVRAS-CHAVES:

Museologia. Gestão museal.

Sustentabilidade. Práticas

socioambientais. Cidadania.

\begin{abstract}
:
Reflect on Museum management practices and its role in the $\mathrm{XXI}$ century. The Museums through their assets, specimens and equipment have the mission of stimulate appreciation of culture, represent the broadest spectrum of human achievement at the highest level of quality, as well as educate and entertain the public. However, these essential activities need to be rethought, because it alone no longer meets the needs of changing times. The study proposes the designing of Museum Planning chart to be applied in situations and examples of social and environmental programs in Brazilian Museums. We conclude that Museum practice should also encourage active community participation in environmental issues and the full exercise of citizenship, placing itself as an institution that enables the reflexivity of the community members before reality.
\end{abstract}

\section{KEY-WORDS: \\ Museology. Management. \\ Sustainability. Community. \\ Citizenship.}

\footnotetext{
I Professor Assistente no Departamento de Ciência da Informação, Fabico/UFRGS, Professor de Museologia. Mestre em Memória Social e Documento. PPGMS/UNIRIO.

2 Professor Adjunto II do Departamento de Ciências da Informação, Fabico/UFRGS. Professor do programa de Pós-Graduação em Comunicação e Informação. Doutor em sociologia, FFLCH/USP.
} 


\section{I.Introdução}

Os Museus têm se tornado instituições de grande sucesso em todo mundo contemporâneo. Seu crescimento se dá por diversos fatores, entre eles, está o novo papel das instituições museológicas na educação, mas também por servir meIhor as necessidades da sociedade. Destaca-se ainda a expansão das coleções, quer seja através de doações ou de fatos históricos, que, ao se tornarem memória, vem sendo valorizados pela sociedade; como a imigração, para citar apenas um exemplo.

O crescimento dos Museus se deve ao aumento das verbas através de isenção de impostos de particulares, mas também pela atenção social pública, uma vez que os objetivos dos Museus atendem questões políticas.Aqui nos referimos a direitos difusos, ou seja, aquela geração de direitos que apareceu depois da II Grande Guerra e que foram consagrados a partir da Declaração Universal dos Direitos do Homem. Assim, em seu artigo 27 afirma:

Toda pessoa tem direito de tomar parte livremente na vida cultural e da comunidade e desfrutar das artes e a participar do progresso científico e dos benefícios que deles resultem.

A Constituição da República Federativa do Brasil de 1988, por sua vez, garante esses mesmos direitos difusos especialmente em seus artigos 215 e 216 que tratam da cultura e do patrimônio cultural brasileiro, respectivamente, entretanto, a nossa Constituição inova ao destacar um capítulo inteiro as questões ambientais sintetizadas seu artigo 225, que diz: "Todos tem direito ao meio ambiente ecologicamente equilibrado, bem de uso comum do povo e essencial a sadia qualidade de vida [...]”.

A multiplicação e diversificação que se observa através do crescimento dos Museus,

[...] não se devem a questões de marketing simplesmente, mas por um anseio popular profundo de prestigiar e participar da produção cultural da sociedade, que são motivadas pela vontade de conservar os vestígios de uma sociedade em mudanças. (HERNANDÉZ, 1998, p. 287).

Segundo Cury, (2009, p. 2) o "Museu deve resistir também a concepção equivocada de desenvolvimento distanciando-o de interesses de segmentação do mercado que buscam o lucro em detrimento de valores sociais e culturais."

O Museu é então 'o olhar do outro' sem amarras como quem vê um quadro pelo lado de fora. Ele é um espaço privilegiado em termos de ferramentas eficazes para propor mudanças, mas também para educar com vistas aos grandes desafios que se impõe neste início de milênio.

\section{A Política Nacional de Museus}

Durante a gestão do Ministério da Cultura entre 2003 e 2006, foram desenhadas as primeiras iniciativas práticas para a política nacional voltada para o setor museológico brasileiro. Em Maio de 2003 foi apresentado o caderno contendo a Política Nacional de Museus - Memória e Cidadania'. O objetivo desta política é:

I INSTITUTO BRASILEIRO DE MUSEUS. Política Nacional de Museus. Brasília, 2003. Disponível em:

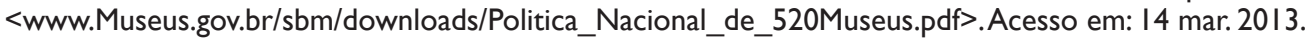


Promover a valorização, a preservação e a fruição do patrimônio cultural brasileiro, considerado como um dos dispositivos de inclusão social e cidadania, por meio de desenvolvimento e da revitalização das instituições museológicas existentes [...] (IBRAM, 2003).

A Política Nacional de Museus apresenta sete pilares de sustentação que estruturam ações a serem desenvolvidas, sendo que a primeira delas compreende a gestão e configuração de processos museológicos. As outras seis são: a democratização e acesso aos bens culturais, formação de recursos humanos, informatização de Museus, modernização da infraestrutura, financiamento e aquisição de acervos e gestão de acervos museológicos.

Para consolidar esta política pública o Governo Federal criou o Sistema Brasileiro de Museus, que é o órgão responsável pela gestão da Política Nacional de Museus. O órgão gestor tem sua composição formada por membros da sociedade civil e do setor governamental, e tem como objetivo propor as diretrizes e as ações para o setor museológico. $A$ entidade funciona através de um formato democrático que garante o debate e permite uma ampla participação da sociedade civil organizada em suas decisões. Assim afirma Storino, (2007, p. 55):

Gestores do Instituto Brasileiro de Museus/IBRAM apontam para a necessidade de se construir na atualidade, modelos democráticos de gestão cultural. Um dos desafios atuais é, segundo eles, o encontro de um ponto de equilíbrio dinâmico, na qual a participação da iniciativa privada, das comunidades populares e dos movimentos sociais não implique na exoneração do Estado no papel que lhe cabe na preservação da memória. [...].

No Brasil, se apresenta como modelo de Gestão de Museus as ações contidas no Plano Museológico, que retirou conceitos e metodologia do Museums \& Galleries Commission (MGC), um órgão britânico criado em 1931. (DAVIES, 200I) Em 2006 o Instituto do Patrimônio Histórico e Artístico Nacional / IPHAN publicou a Portaria Normativa $\mathrm{n}^{\circ} 0 \mathrm{I}$, assinada pelo Presidente do órgão, sobre a obrigatoriedade de elaboração do Plano Museológico nos Museus do IPHAN: "O ato é inovador no campo museológico e servirá de base para que outros Museus, não vinculados ao Iphan, possam adotá-lo para elaboração de seus próprios planos museológicos" (BRASIL, 2006). Em Janeiro de 2009, a Lei I I.9042, que institui o Estatuto de Museus, estendeu essa obrigatoriedade para todos os Museus públicos brasileiros. Como expõe Silvana Cançado, da Secretaria de Cultura do Estado de Minas Gerais:

[...] a Seção III do Estatuto de Museus, artigos 44 a 47, é dedicada ao Plano Museológico, estruturando-o e estabelecendo seu conteúdo. Essa Lei encontra-se em pleno vigor e deverá nortear todos os procedimentos afetos às instituições museológicas no Brasil (CANÇADO, 2010, p. 9).

O documento apresenta os procedimentos para a organização e gestão dos Museus públicos brasileiros, além de detalhar as diretrizes e procedimentos para elaboração do Plano Museológico, indicando inclusive, quais programas ele deve conter e está dividido em três partes, a saber:

2 Texto completo da Lei disponível em: <http://www.planalto.gov.br/ccivil_03/_Ato2007-2010/2009/Lei/ LI I 904.htm>.Acesso em: I5 jan. 2009. 
Introdução: Questões da instituição, histórico, regimento interno, metas e missão.

Programas:A que se dispõe a instituição, através de que meios. Gestão, finanças, arquitetura, aquisição, conservação, segurança, pesquisa, educação e cultura.

Projeto de gestão: Como se pretende gerir o patrimônio e o acervo: orçamento e também como fazer para conservar e exibir.

Analisando as informações contidas no Plano Museológico, quando detaIhadas através de suas diversas ações, é possível adaptar o planejamento para toda a diversidade, variedade e a ampla tipologia que os Museus e centros culturais assumem na prática.

As informações sugerem uma reestruturação por meio de um roteiro administrativo para Museus já implantados ou em funcionamento, mas também para aqueles em fase de projeto. A primeira parte compreende desde a formulação da missão e mandato, mas também a formatação jurídica do Museu, seu estatuto e regimento interno, tipo institucional de governança, código de ética entre outras formalidades. Estes conteúdos devem estar conectados com a realidade e a prática dos Museus através de um constante exercício de diagnóstico e avaliação. Esta prática torna-se essencial, em instituições que lidam com $\mathrm{Pa}$ trimônio Cultural, exposições, pesquisa, coleções, documentação, aquisições e descarte de acervo, entre outras funções típicas de Museus.

É através da segunda parte do Plano Museológico, dedicado aos programas, que se podem ordenar as atuações em cada âmbito do Museu, que inclui a relação das necessidades para o cumprimento de suas funções que se concretizarão em diferentes projetos. Também deve compor a pauta social do Museu ao incluir entre um de seus programas as questões socioambientais e de cidadania. Essas temáticas não podem ser esquecidas quando tratamos de Gestão de Museus. Tais questões estão na agenda social e necessitam de encaminhamento e debate entre a comunidade universitária e a sociedade. As questões socioambientais que se impõe na agenda política e social no mundo contemporâneo, quando não encaminhadas, têm trazido consequências devastadoras a natureza e os efeitos da falta de articulação entre as questões de educação ambiental podem causar danos a todo o sistema social. De acordo com Álvares (20 I 2, p. I2): Aos Museólogos, cabe abraçar as dinâmicas da mudança social, acentuar a voz do nacionalismo histórico e contemporâneo, remover homogeneidade e pontos de vista único, rejeitar a exclusão, incentivar a complexidade e o pluralismo, tornando-o local para o diálogo da identidade nacional e da inclusão social. Aos professores de Museologia, cabe a formação obrigatória também do cidadão.

A terceira parte do Plano Museológico é dedicada aos projetos. Esses projetos são derivativos dos programas e se caracterizam por serem documentos executáveis que possibilitam a materialização das especificações técnicas reconhecidas nos diferentes programas. Nos projetos são definidas, descritas e propostas as soluções ajustadas para as necessidades das instituições no cumprimento de suas missões.

Assim, conclui-se que os Museus devem considerar a inserção em seu Plano Museológico, desde a missão e objetivos, passando pelos programas e projetos uma especial atenção as questões socioambientais. Desta forma eles se colocam em consonâncias com as demandas dos novos tempos e se mantêm na vanguarda das mudanças sociais. 


\section{Processos e questões: a gestão sustentável}

Para Yudelson (2008, p. 55):

[...] gestão sustentável é a capacidade de gerenciar um empreendimento por meio de processos que valorizem e aprimorem capitais naturais, financeiros e humanos, conciliando diferenças e pontos de vista díspares em prol de objetivos comuns.

Mas, afinal, a que se refere o conceito de sustentabilidade? E, como podemos reconhecer um empreendimento culturalmente sustentável?

Apesar das controvérsias em torno desta questão, segundo as Nações Unidas, um empreendimento para ser sustentável deve ser: socialmente "justo", economicamente viável e ambientalmente aceitável. De acordo com Nascimento (2012, p. 8):

Nos embates ocorridos nas reuniões de Estocolmo (1972) e Rio (1992), nasce a noção de que o desenvolvimento tem, além de um cerceamento ambiental, uma dimensão social. Nessa, está contida a ideia de que a pobreza é provocadora de agressões ambientais e, por isso, a sustentabilidade deve contemplar a equidade social e a qualidade de vida dessa geração e das próximas. A solidariedade com as próximas gerações introduz, de forma transversal, a dimensão ética.

A sustentabilidade encontra-se na interseção entre essas três forças que estão presentes em nossas realidades: a social, a econômica e a ambiental. No caso de empreendimentos culturais como Museus, exposições de arte, históricas ou científicas, sítios culturais em suas mais diversas formas, também serão sustentáveis quando se introduz um quarto elemento na fórmula acima mencionada.

"A disseminação da cultura é justamente o quarto elemento, que juntamente como o econômico, o social e o ambiental vão possibilitar que um empreendimento seja culturalmente sustentável” (LORD, 2009, p. 22). É através de práticas e exemplos que promovam a consciência e o desenvolvimento cultural das pessoas que se pode evitar que as atividades humanas não irão se voltar contra a própria sociedade no futuro. Um exemplo disso é a falta de critério na reciclagem de resíduos sólidos que infestam o meio ambiente ou na emissão, muitas vezes desnecessária, de gases nocivos como o dióxido de carbono na atmosfera.

\section{I A sustentabilidade econômica}

Como coloca Rendeiro, $(201$ I, p. 6$)$ a sustentabilidade econômica se aplica no Museu através de recursos financeiros que é sempre limitado.

O atual estado de carência financeira que afeta os Museus nacionais obriga a que se reformulem os modelos de gestão vigentes. Nesse sentido, tendo em conta as medidas de austeridade, os cortes orçamentais, as reestruturações na administração central, entre outros fatores que perturbam o setor cultural e que colocam os Museus nacionais nas mais críticas condições de sobrevivência, torna-se premente que se estabeleçam linhas de atuação que os reintegrem no desenvolvimento da sua missão.

Gastar os recursos disponíveis de forma eficaz é vital para manter a transparência e a confiança dos patrocinadores, do público e do governo. O Museu 
deve investir cada centavo que ganha em seu 'próprio' benefício, que é coletivo. Nesse sentido, uma gestão pautada em princípios éticos, através de escolhas bem feitas, planejamento cuidadoso e atenção ambiental podem garantir seu crescimento e mais importante; manter-se no tempo. Simples ações de gestão que vão desde a escolha de matérias economicamente eficientes até a implantação de sistemas de monitoramento contra desperdícios podem ajudar na sustentabilidade econômica do Museu.

\subsection{A sustentabilidade socioambiental}

A sustentabilidade ambiental é um dos assuntos que exercem grande pressão global na atualidade; os Museus devem estimular discussões sobre educação ambiental pública e dar o exemplo de práticas ambientais corretas. $\bigcirc$ meio ambiente no qual realizamos nossas atividades cotidianas, por sua vez também exerce impacto em cada aspecto da cultura humana, da natureza e da história. Cada Museu, independentemente de sua especialidade, através da sua programação pode contribuir no processo reflexivo em relação à sustentabilidade e ao nosso futuro no planeta. Como afirma Correia (2012, p. 87):

O desenvolvimento sustentável tem se tornado um desafio para toda e qualquer atividade que tem compromisso socioambiental. A sustentabilidade ambiental consiste em um novo paradigma que deve ser alcançado, sob pena de os custos ambientais serem tão elevados para a sociedade e muitas atividades humanas não poderem persistir num futuro muito próximo. Todos nós dependemos dos recursos naturais e ambientais, e, portanto, nesta perspectiva temos de prolongar a vida útil desses recursos.

A sustentabilidade social é o que dá ânimo ao Museu; especialmente se o trabalho realizado nele repercutir nas ações de cada membro da comunidade, tornando um sujeito participativo e coresponsável pela construção da coletividade. Entretanto, é necessário trabalhar na direção de questionar estilos de vida baseados em padrões do consumismo e do desperdício.

Uma sociedade sustentável que promova a qualidade de vida dos seus cidadãos necessita estar vigilante aos processos de gestão da produção, circulação, consumo e destino dos resíduos.A participação comunitária na resolução e encaminhamento de problemas socioambientais possibilita a compreensão de que as práticas do passado são capazes de definir o presente e estas redefinirem as gerações do futuro.

\subsection{A sustentabilidade cultural}

No mundo contemporâneo, o papel do Museu não se limita a ser o "guardião" da herança cultural do passado. O Museu é um espaço de reflexão, discussão, de debates sobre as questões que nos inquietam no presente e, ao mesmo tempo, pode servir de 'abrigo' a elas, transpassando os tempos, auxiliando os cidadãos construírem um mundo mais sustentável.Assim, pensar na gestão de um Museu significa repensar práticas, rever ações, debater, questionar, mobilizar e, sobretudo, participar socialmente da criação de uma cultura para construção de um mundo mais sustentável.

Um exemplo de Museu e sustentabilidade no século XXI é o projeto de construção e gestão do Museu de Imagem e do Som - MIS, que está sendo 
edificado no Rio de Janeiro. Segundo os planos de implantação do MIS, ele já vai nascer com um projeto arquitetônico que leva em conta as questões ambientais e de sustentabilidade. Seu objetivo é conquistar de uma Organização não Governamental (ONG) a certificação LEED (Leadership in Energy and Environmental Design) ouro, ou seja, bem acima das metas mínimas necessárias para obtenção desta certificação ambiental internacional de sustentabilidade3. O MIS/RJ manterá diálogo constante com a comunidade do entorno do Museu, através de uma sala exclusiva para este fim. Também está previsto um programa permanente de palestras periódicas com o público e com os funcionários do Museu sobre o conceito de sustentabilidade e educação ambiental.

\section{Gestão museal: o plano museológico e os manuais de gestão}

Cotejando a produção bibliografia disponível para a didática e o ensino da Gestão museológica, percebemos que há poucos trabalhos, a maioria em forma de manuais cujos autores são europeus ou norte-americanos. No entanto, destacamos dois títulos que são dignos de referencia. O primeiro da professora da Universidade Complutense de Madrid, Francisca Hernández 'Manual de Museologia'.

Trata-se de um manual de 300 páginas que abrange todos os aspectos museológicos que vão desde a história dos Museus, passando pela arquitetura deles, exposições museológicas, ações educativas em Museus, conservação e proteção de bens culturais, programas de Museus até a disciplina que nos interessa, e que pela autora foi chamado de "Administração, Gestão e Organização de Museus" (tradução dos autores).

No capítulo correspondente a Gestão de Museus o manual trata das características das administrações a partir dos tipos de instituições espanholas: Museus estatais, particulares, eclesiásticos e fundações mantenedoras com suas características diferenciadas, para finalmente entrar especificamente na área de Gestão de Museus.

Observa-se entre as páginas $\mathrm{IOI}$ a $\mathrm{II}$, como são abordados assuntos inerentes as funções de um Museu como as áreas de conservação e pesquisa, difusão e administração, direção e os diversos profissionais que trabalham dentro de uma instituição museológica; restauradores, conservadores, Museólogos entre outros. A autora discorre sobre um tema que julgamos interessante para a área de gestão, o qual chamou de: mudanças sociais e as novas perspectivas da Museologia. Neste capítulo são tratados os seguintes temas como a relação aos Museus: A civilização do ócio, a cultura de massas, marketing, recursos e economia, novas tecnologias aplicadas, e o Museu numa sociedade pós-moderna.

Outro título interessante é o Manual of Museum Management4 de Gail e Barry Lord. O casal canadense atua no ramo da Museologia por mais de quatro décadas e são proprietários da empresa Lord Cultural Resources que projeta, constrói, equipa, treina pessoal e administra Museus por todos os continentes. O Manual de Gestão Museológica (tradução livre), em sua segunda edição de

3 No projeto está previsto uma economia de energia de $26 \%$, e de água em $35 \%$ através de sistemas eficientes como captação de luz do meio ambiente e de energia solar, reaproveitamento das águas utilizadas nos serviços do Museu, uso de lâmpadas e luminárias de alta eficiência, sistema de monitoramento contra vazamentos e desperdício de energia e iluminação inteligente nas dependências do Museu. SECRETARIA DE CULTURA DO ESTADO DO RIO DE JANEIRO. Site. Disponível em: <http://www.cultura.rj.gov.br/ espaco/Museu-da-imagem-e-do-som-mis>. Acesso em: 14 mar. 2013.

4 O livro foi traduzido para o espanhol e publicado na Espanha. Um dos autores deste artigo, por iniciativa própria, traduziu a obra do original em inglês, sendo que, atualmente encontra-se em fase de negociação com os autores canadenses para uma edição em português no Brasil. 
2009, tem 330 páginas dedicadas exclusivamente a Gestão de Museus. O livro está dividido em três partes: A primeira chamada de 'Por quê?' e abrange os aspectos dos propósitos da gestão, da missão e do papel da gestão de um Museu. A segunda parte chamada de 'Quem?' trata da estrutura organizacional do Museu, de seus diversos modos de governança, do conselho, do papel dos voluntários e do papel da sociedade civil no Museu. A terceira e última parte, chamada de 'Como?', abrange os métodos de gestão e as suas diversas gerências: coleções, programas públicos, arquitetura e finanças.

\section{I O papel da museologia e dos museólogos}

A abertura de mais de uma dezena de cursos de Museologia no Brasil, a partir de 2008, vem mudar o quadro da oferta de profissionais no mercado de trabalho dos Museus. As universidades através da criação dos cursos de Museologia, já estão capacitando profissionais para atuar nas centenas de Museus brasileiros, que até então, não podiam contar com a colaboração desses profissionais, uma vez que os dois únicos cursos que havia5, não poderiam dar conta desta demanda em nível nacional e nem tão pouco em nível regional6.

A nova realidade liga-se a formação dos Museólogos, passa pelos currículos das escolas de Museologia, e também pela questão de onde se inserem os cursos dentro das universidades brasileiras. Neste sentido, a formação do Museólogo dialoga com diferentes e variados corpus de saberes que vão desde a Ciência da Informação, da História, das Artes Visuais, da Antropologia, da Administração, da Geografia e da Biologia. De acordo com Álvares, (2012, p. 43).

Os Museus e, por conseguinte, os Museólogos tem o notável dever de representar a identidade nacional. Os debates sobre $o$ assunto realçam novos desafios para a profissão em torno da questão, dentre eles, a promoção da integração nacional dentro da pluralidade e diversidade de identidades regionais.

Como um campo de saber multidisciplinar por natureza, a Museologia e as práticas dos novos Museólogos, podem criar tensões com outros profissionais de diferentes áreas e que realizam atividades a mais tempo do que eles em diversos segmentos dentro dos Museus. Esses profissionais estão em posições nas quais dominam com natural competência, e o desafio dos egressos dos novos cursos de Museologia tem um efeito positivo.

A colocação de novos Museólogos nos quadros dos Museus vai exigir deles a conquista de espaços pelo mérito, mas também através dos conhecimentos e aprendizados que lhes foram comunicados em seus respectivos cursos. Isto traz novas inquietações dentro das universidades e neste contexto, mostra a necessidade de abertura e diálogo com áreas já consolidadas no espaço acadêmico sobre a conveniência e o lugar do curso de Museologia, ao lado ou vinculado a esta ou aquela área de conhecimento. Assim afirma Stuart, (2012, p. 63)

Pontos de vistas variados; diversidade; estímulo ao senso crítico; abertura; respeito a diferentes opiniões; confronto de ideias; contextualização cultu-

5 Rio de Janeiro - UNIRIO e Bahia - UFBA.

6 É inegável constatar que ambos os cursos mais antigos sofreram o impacto desta 'avalanche' de novos cursos. Apesar de possíveis resistências, uma série de novas ideias trazidas por intelectuais, professores, pesquisadores e cientistas da informação, que atuam nesses novos cursos, dinamizaram o que estava estagnado e uma profícua discussão que envolve os currículos dos cursos de Museologia está acontecendo atualmente na maioria das universidades onde há este curso de graduação. 
ral e histórica; olhares multidisciplinares; consciência cidadã; estas e outras estratégias e valores devem estar presentes nas exposições dos Museus caso queiramos que estes espaços sejam promotores da cidadania.

Há grande diversidade das tarefas conduzidas nas dependências de um Museu, por um número de variados profissionais. Arquitetos podem organizar exposições não só do ponto de vista técnico estrutural, mas também enquanto desenhistas (planejadores) de exposições, ou na museografia dessas exposições. Historiadores e antropólogos encontram colocação junto às coleções dos Museus e produzindo planos interpretativos para exposições, Sociólogos estão aptos a realizar e analisar pesquisas de público em Museus, Administradores são bons gestores, mas também podem preparar processos de captação de recursos. Historiadores da Arte, Biólogos e Arqueólogos são curadores de exposições e os Educadores os responsáveis pelos projetos pedagógicos dos Museus. Todas as áreas possibilitam a criação de um espaço para a colaboração de Museólogos que podem enriquecer o trabalho e a visão de todos esses profissionais.

Há poucos trabalhos publicados sobre Gestão de Museus, especialmente se considerarmos a abordagem transdisciplinar. Obviamente refletir sobre processos de gestão é, em si, uma tarefa complexa, e de Museus, torna-se mais complexa, com suas funções muito específicas. Reunir informações técnicas em lições acadêmicas requer sistematização e aproximação anterior a alguns conceitos, assim como a necessidade de articular de forma didática e compreensiva essas duas ciências;Administração e Museologia. Este é o desafio que se impõe.

Entre os processos de gestão de um Museu, a prática da avaliação de suas atividades e funções é um elemento indispensável porque proporciona transparência e participação democrática de todos os envolvidos; gestores, colaboradores e o público. Dessa forma ensina Cury (2009, p. 02) "Relacionar-se com o patrimônio é um processo, é um exercício democrático sistemático é um processo educacional no seu sentido amplo, mas profundo".

A avaliação se dá de forma interna e externa no âmbito do Museu. A análise interna ocorre em nível de cada colaborador que ocupa uma função específica em um determinado setor do Museu. A avaliação visa promover um diagnóstico da eficiência e da eficácia de cada um que está inserido no quadro funcional da instituição. A avaliação serve para encontrar os problemas e trabaIhar suas soluções, fixar estratégias de ações para o efetivo encontro das metas de longo prazo, que foram definidas e controlar os cumprimentos dos diversos objetivos, dentro dos prazos que foram previamente estipulados.

A avaliação externa se dá em relação a imagem que o Museu projeta perante a comunidade de uma maneira geral, frequentadores avulsos, grupos de turistas, nacionais e estrangeiros, professores e estudantes de todos os níveis, além de pesquisadores e cientistas. A avaliação externa mede o grau de satisfação de cada um desses grupos de pessoas separadamente e o sucesso do empreendimento museal em suas visões e, em relação a missão da instituição.

De acordo com Lord, (2009, p. 22) a principal função do gestor de Museus é "facilitar a circulação de decisões". Tais decisões devem visar o cumprimento da missão da casa, que por sua vez devem estar em consonância com as políticas traçadas para ela. $\bigcirc$ gestor é o principal incentivador do cumprimento da missão do Museu junto aos colaboradores e visitantes, sendo que, a sua inspiração reflete no dia a dia da instituição, interna e externamente, em seus diversos setores, tornando o gestor uma liderança que todos no Museu naturalmente seguem. Conforme Lord (2009, p. 23): 
É parte das atribuições do gestor de Museus comunicar o mandato da instituição aos colaboradores e ao público em geral.É importante que todos tenham consciência plena dos limites deste mandato, principalmente em relação a outras instituições, inclusive a universidade7.

Isso é importante para que o Museu conheça bem o seu objeto e evite perder o próprio foco, entrando no campo de outro Museu ou instituição, mas também para que cada um dos colaboradores saiba exatamente sua função e responsabilidades dentro deste quadro. Para Lord (2009, p. 24), o modo como se avalia o gestor é simples;

[...] deve-se questionar se o gestor está ou não facilitando a circulação de decisões para que se cumpra a missão do Museu, e se ele está ou não comunicando bem o mandato do Museu à todos.

Assim, segundo o mesmo autor, (LORD, 2009, p. 25) é tarefa do gestor é: "[...] controlar o cumprimento das grandes metas do Museu, dentro de um orçamento e calendário de objetivos menores.” Para isso ele deve: avaliar a eficiência e a eficácia do pessoal do Museu em relação ao cumprimento das metas estabelecidas, e o esforço que cada um dos colaboradores realiza para que tais metas sejam cumpridas dentro do tempo estabelecido, levando em conta o espaço que cada um ocupa (que no Museu tende a ser pequeno) e a produtividade em relação as suas tarefas. Assim descreve Lord, (2009, p. 26):

Eficácia: Mede a extensão na qual os esforços do Museu encontram o resultado pretendido, e que deveriam estar quantificados o máximo possível em detalhes no Plano Museológico para aquela função específica. Eficiência: Mede o efeito em relação ao esforço desprendido - em pessoas/horas, em dinheiro, em espaço (que são raros nos Museus) ou em uso de equipamento. $O$ termo custo-eficácia é usado muitas vezes para descrever eficiência em termos financeiros: gente-eficiência ou espaço-eficiência são também usados para descrever eficiência. (Tradução e grifos dos autores)

O autor canadense (LORD, 2009, p. 28) pondera que nos últimos anos [...] os Museus têm se tornando mais alinhados com as instituições da sociedade civil em suas diversas fontes de financiamentos pelas comunidades, patrocinadores e mecenatos, públicos e privados.

Isso, segundo ele, desafia a ideia de que os Museus devem ser avaliados apenas por suas funções profissionais, mas que (LORD, 2009, p. 29):

[...] existe uma forte tendência de se avaliar o Museu em termos dos seus resultados, mas também pela contribuição para com a sociedade de forma geral.

E conclui relatando que (LORD, 2009, p. 30):

[...] no Reino Unido esta avaliação se dá em termos de critério de inclusão social enquanto na América do Norte há uma tendência de se avaliar os programas museológicos e suas coleções em termos de diversidade a quem servem e representam, mas que, em ambos os casos, a avaliação se dá em termos de resultados sociais.

7 Alguns Museus universitários têm entre suas funções a pesquisa de ponta, porém os Museus que não são vinculados a academia, segundos os autores (p.23), devem estar limitados aos conhecimentos reconhecidos e transmitidos por ela, ou caso seja possível, encaminhar suas pesquisas através das universidades. 
No âmbito do Plano Museológico o exercício de avaliação também é realizado de maneira interna e externa, mas também de forma coletiva pelos colaboradores em seus diversos setores, juntamente com as lideranças da Gestão do Museu. $\mathrm{Na}$ prática é realizado um diagnóstico que avalia e leva em conta o estado atual do Museu em relação as suas metas. $\bigcirc$ diagnóstico articula as seguintes variáveis: Pontos fortes, Pontos fracos, Oportunidades e Ameaças. (conhecido na administração como análise SWOT - Strong and Weak points, Oportunities and Treats).

\section{Considerações finais}

Assim, tomou lugar no país um amplo debate sobre o papel da Museologia contemporânea, tendo os Museus como agentes de inclusão cultural, de afirmação de identidades de grupos sociais, de reconhecimento da diversidade e de desenvolvimento econômico aliado às questões da sustentabilidade.

As discussões sobre a sustentabilidade socioambientais tornaram-se urgentes e dependem da educação para o meio ambiente, tanto para crianças como para adultos serem agentes de mudanças e compreenderem melhor o complexo mundo que lhes cercam. É neste sentido que o Museu contemporâneo deve se inserir, utilizando suas ferramentas de comunicação, informação, educação e entretenimento para proporcionar o entendimento e uma consciência social, por exemplo: da fragilidade da natureza e dos recursos não renováveis diante de um mundo cheio de contradições e que sofre pressões, até certo ponto legítimas para uma prática equivocada de um consumismo desenfreado e nefasto ao próprio cidadão.

O Museu pode trazer diferentes olhares e contrapontos sobre as questões socioambientais, uma vez que é relativamente 'livre' de pressões comerciais e pode proporcionar a população uma visão realista da necessidade das comunidades e consumidores, que, ao se articularem em torno do exercício organizado da cidadania, exigir tanto das empresas quanto do poder público, providências para que as gerações futuras não sofram as piores consequências de seus atos que são praticados impunemente e sem a menor consciência de suas consequenciais socioambientais na atualidade.

Desta maneira, inserido no Museu junto a outros profissionais de diferentes áreas, que o Museólogo passa a participar de uma ampla rede de saberes, ganhando força para aquisição de uma identidade própria e uma prática coerente frente a outras disciplinas acadêmicas já consolidadas.

É possível que o Museu contemporâneo seja o maior exemplo de multidisciplinaridade em um mundo informatizado e digital. É nos Museus, nas bibliotecas e nos arquivos que se encontram os registros e as memórias das diversas ciências. Neles se exibem, guardam e comunicam os avanços científicos e culturais e suas apropriações podem fazer a diferença para a construção de uma sociedade mais justa e igualitária.A prática museológica também deve fomentar a participação ativa da comunidade em questões socioambientais e do exercício pleno da cidadania, colocando-se como instituição que possibilita a reflexividade dos sujeitos diante da realidade.

Assim o Museólogo traz, em fim, para o Museu, um certo 'olhar do outro' que é apenas mais um ponto de vista, mas que pode auxiliar na compreensão e nas diferentes necessidades de uma sociedade que respeita a diversidade. 


\section{Referências}

ÁLVARES, Lilian. Graduação em Museologia: significados, opções e perspectivas. Revista do Programa de Pós Graduação da Ciência da Informação da UnB, Brasília, ano I, n. I, p. 236-250, 2012.

BRASIL. Instituto do Patrimônio Histórico Artístico Nacional. Portaria Normativa $n^{\circ}$ I 05/07/2006 Plano Museológico dos Museus do IPHAN. Diário Oficial da União, Brasília, Seção I, I I jul. 2006.

CANÇADO, Silvana Trindade. Planejamento museológico: caderno 02. Belo Horizonte: Secretaria de Estado de Cultura, Superintendência de Museus e Artes Visuais de Minas Gerais, 2010.

CORREIA, Mary Lucia Andrade. Como Alcançar a sustentabilidade ambiental? Jornal da Universidade de Fortaleza, Fortaleza, n. 219, jun. 2012.

CURY, Marília Xavier. Museu em transformação. Revista Museu, maio 2009. Disponível em: <http://www.revistaMuseu.com.br//8demaio/artigos.asp?id=328 46>. Acesso em: 25 fev. 2013.

DAVIES, Stuart. Plano diretor.Tradução de Maria Luiza Pacheco Fernandes. São Paulo: Editora da Universidade de São Paulo; FundaçãoVitae, 200I. (Série Museologia, I).

INSTITUTO BRASILEIRO DE MUSEUS. Política Nacional de Museus. Brasília, 2003. Disponível em: <www.Museus.gov.br/sbm/downloads/Politica_Nacional_ de_520Museus.pdf>.Acesso em: I 4 mar. 2013.

LORD, Gail;LORD, Barry. Manual of museum management Toronto:Altamira Press, 2009.

HERNADÉZ, Francisca. Manual de museología. Madrid: Editorial Sintesis, 1998.

NASCIMENTO, Elimar Pinheiro do.Trajetória da sustentabilidade: do ambiental ao social, do social ao econômico. Revista do Instituto de Estudos Avançados da Universidade de São Paulo, São Paulo, v. 26, n. 74, 2012.

PINHEIRO, Lena Vânia Ribeiro. Confluências interdisciplinares entre ciência da informação e museologia. Museologia e interdisciplinaridade Revista do Programa de Pós Graduação da Ciência da Informação da UnB, Brasília, ano I, n. I, p. 9-25, 2012.

RENDEIRO, Humberto. Museus e sustentabilidade financeira. In: ICOM - PORTUGAL, NO MUSEU NACIONAL DE SOARES DOS REIS, Cidade do Porto, 7 nov. 20I I.Anais... Cidade do Porto, 20I I.

STORINO, Claudia. Museus sob nova direção.Jornal do Brasil, Rio de Janeiro, 4 mar. 2007.

STUART, Denise. Museus e centros de ciências na esteira da diversidade e da cidadania. Museologia e interdisciplinaridade Revista do Programa de Pós Graduação da Ciência da Informação da UnB, Brasília, ano I, n. I, p. 26-37, 2012.

YUDELSON, Jerry. The green building revolution. Island Press, Washington DC, 2008. Disponível em: <http://www.Museus.gov.br/publicacoes-e-documentos/4-forum-nacional-de-Museus/>.Acesso em: I 4 mar. 2013. 